\title{
Oxidative Stress in Lead and Cadmium Toxicity and Its Amelioration
}

\author{
R. C. Patra, ${ }^{1,2}$ Amiya K. Rautray, ${ }^{1}$ and D. Swarup ${ }^{2,3}$ \\ ${ }^{1}$ Department of Medicine, College of Veterinary Science and Animal Husbandry, Orissa University of Agriculture and Technology, \\ Bhubaneswar 751003, India \\ ${ }^{2}$ Division of Medicine, Indian Veterinary Research Institute, Izatnagar 243122, India \\ ${ }^{3}$ Central Institute for Research on Goats, Makhdoom 281122, UP, India
}

Correspondence should be addressed to R. C. Patra, rcpatra@gmail.com

Received 12 January 2011; Accepted 21 January 2011

Academic Editor: Cristina Castillo Rodríguez

Copyright ( $) 2011$ R. C. Patra et al. This is an open access article distributed under the Creative Commons Attribution License, which permits unrestricted use, distribution, and reproduction in any medium, provided the original work is properly cited.

Oxidative stress has been implicated to play a role, at least in part, in pathogenesis of many disease conditions and toxicities in animals. Overproduction of reactive oxygen species and free radicals beyond the cells intrinsic capacity to neutralize following xenobiotics exposure leads to a state of oxidative stress and resultant damages of lipids, protein, and DNA. Lead and cadmium are the common environmental heavy metal pollutants and have widespread distribution. Both natural and anthropogenic sources including mining, smelting, and other industrial processes are responsible for human and animal exposure. These pollutants, many a times, are copollutants leading to concurrent exposure to living beings and resultant synergistic deleterious health effects. Several mechanisms have been explained for the damaging effects on the body system. Of late, oxidative stress has been implicated in the pathogenesis of the lead- and cadmium-induced pathotoxicity. Several ameliorative measures to counteract the oxidative damage to the body system aftermath or during exposure to these toxicants have been assessed with the use of antioxidants. The present review focuses on mechanism of lead- and cadmium-induced oxidate damages and the ameliorative measures to counteract the oxidative damage and pathotoxicity with the use of supplemented antioxidants for their beneficial effects.

\section{Introduction}

The diverse deleterious health effect upon exposure to toxic heavy metals in the environment is a matter of serious concern and a global issue. Much emphasis has been given to elucidate the mechanism of toxicity due to common environmental toxicants and to develop a safer chemotherapeutic approach to mitigate the toxic effects. Lead and cadmium are the two most abundant toxic metals in the environment. The coexposure to these two toxic metals has synergistic cytotoxicity that may, at times, turn to antagonistic effects, because exposure to higher mixture concentrations may enhance cellular defense mechanisms [ 1 , 2 ], including induction of metallothioneins synthesis upon exposure to cadmium. The concurrent higher levels of lead and cadmium have been recorded in several field situations. The common sources of lead and cadmium are diverse in nature including natural and anthropogenic processes such as combustion of coal and mineral oil, smelters, mining and alloy processing units, paint industries, and so forth. [2-5]. The quantity of lead used in the present decade far exceeds the total amount consumed in all previous eras [2]. The anthropogenic activities and vehicular emissions contribute to the entry of toxic metals to humans and other animals food chains [6].

Cadmium is an important environmental pollutant present in soil, water, air and food. Anthropogenic sources add 3-10 times more cadmium to the atmosphere than natural sources [7]. Major occupational exposure occurs from nonferrous smelters during production and processing of cadmium, its alloys, and compounds, and the exposure is increasingly common during recycling of electronic waste.

Lead and cadmium do not have any detectable beneficial biological roles. On the contrary, their detrimental effects on physiological, biochemical, and behavioral dysfunctions have been documented in animals and humans by several 
investigators $[8,9]$. The higher levels affect the central and peripheral nervous systems [10], haemopoietic system [11], cardiovascular system [12], kidneys [13], liver [14], and reproductive systems $[15,16]$. Cadmium is more toxic than lead and causes renal and hepatic damage in exposed animals $[13,14]$.

Of late, lead- and cadmium-induced tissue damages have been attributed, at least in part, to toxicant-induced oxidative stress $[17,18]$. Cadmium stimulates the formation of metallothioneins and reactive oxygen species (ROS), thus causing oxidative damage to erythrocytes and various tissues resulting in loss of membrane functions [19]. Long-term exposure to $\mathrm{Cd}$ increases lipid peroxidation and causes inhibition of SOD activity indicating oxidative damage in liver, kidney and testes [20]. The various toxic effects induced by $\mathrm{Cd}$ in biological systems have been linked to increased lipid peroxidation, an as early and sensitive consequence of $\mathrm{Cd}$ exposure. The increase in lipid peroxidation due to $\mathrm{Cd}$ toxicity have been attributed to alterations in the antioxidant defense system which includes enzymes such as glutathione peroxidase (GPx), glutathione-S-transferase, superoxide dismutase (SOD), and catalase (CAT), and nonenzymatic molecule like glutathione, which normally protect against free radical toxicity.

\section{Lead-Induced Oxidative Stress}

The mechanism of lead-induced oxidative stress involves an imbalance between generation and removal of ROS (reactive oxygen species) in tissues and cellular components causing damage to membranes, DNA and proteins. The presence of double bonds in the fatty acid on cell membrane weakens the $\mathrm{C}-\mathrm{H}$ bonds on the carbon atom adjacent to the double bonds and makes $\mathrm{H}$ removal easier. Therefore, fatty acids containing zero to two double bonds are more resistant to oxidative stress than polyunsaturated fatty acids with more than two double bonds [21]. The above fact was substantiated after incubation of linoleic, linolenic, and arachidonic acid with lead in which the concentration of a final product of oxidative stress, malondialdehyde (MDA) was increased with the number of double bonds of fatty acid [22].

The intrinsic mechanism underlying lead-induced oxidative damage to membranes is associated with changes in its fatty acid composition [23]. The fatty acid chain length and unsaturation are the determinant for membrane susceptibility to peroxidation, and lead induced arachidonic acid elongation might be responsible for the enhanced lipid peroxidation of the membrane [24]. Thus, lead affects membrane-related processes such as the activity of membrane enzymes, endo- and exocytosis, transport of solutes across the bilayer, and signal transduction processes by causing lateral phase separation [25].

Lead accumulation in tissues causes oxidative DNA damages including strand break, although the evidence of lead-induced oxidative damage to DNA is less conclusive [18]. The $\delta$-aminolevulinic acid dehydrase (ALAD) is highly sensitive to the toxic effects of lead [26]. The accumulation of $\delta$-aminolevulinic acid (ALA) upon exposure to lead induces generation of ROS $[27,28]$ and resultant oxidative stress [29]. The final oxidation product of ALA, 4,5dioxovaleric acid is an effective alkylating agent of the quinine moieties within both nucleoside and isolated DNA [30]. Increased level of 8-oxo-7, 8-dihydro-2-deoxyguanosine and 5-hydroxyl-2-deoxycytidine following chronic treatment with ALA in rats has been attributed for ALA-induced DNA damage [31]. There are recent data suggesting lead-induced alteration in gene expression [32] and it appears to interact with zinc-binding sites on an important DNA-associated protein, human protamine [33].

The effect on the antioxidant defense systems of cells is the second mechanism for lead-induced oxidative stress. Lead and other metals such as $\mathrm{Hg}$ and Cd have a high affinity for sulfhydryl (SH) groups. Mercaptides are formed with the SH group of cysteine, that are less stable complexes [34]. Lead is shown to alter antioxidant activities by inhibiting functional SH groups in several enzymes such as ALAD, superoxide dismutase (SOD), catalase (CAT), glutathione peroxidase (GPx), and glucose-6-phosphate dehydrogenase (G6PD) [35-38]. G6PD contains many SH group and supplies cells with most of the extramitochondrial NADPH through the oxidation of glucose-6-phosphate to 6-phosphogluconate. G6PD is inhibited by lead [39]. However, there are more complex effects of lead on G6PD, as evidenced by in vivo studies. G6PD activity increases in RBCs of lead-treated rats [40] and lead-exposed workers [41]. The most important regulation of the pentose phosphate pathway is the NADP/NADPH ratio, which is known to change in favor of the oxidized form under oxidative stress conditions. Therefore, lead exposure results in an increase or decrease in G6PD activity depending on the concentration and duration of lead exposure, and magnitude of oxidative stress inside the cell [42].

GPx, CAT, and SOD are potential targets for lead toxicity because these antioxidant enzymes depend on various essential trace elements for proper molecular structure and activity [43]. Since lead-associated reduction in selenium uptake may increase the susceptibility of the cell to oxidative stress, an antagonistic effect between selenium and lead was found to affect GPx activity that requires selenium as a cofactor [44]. On the other hand, administration of selenium before lead exposure produces significant prophylactic action against lead-induced oxidative stress by means of increasing SOD, glutathione reductase (GR) activity, and glutathione (GSH) content in male rats [45]. In summary, impaired antioxidant defenses can be a result of the inhibitory effects of lead on various enzymes, which in turn causes the cells to be more susceptible to oxidative insult.

\section{Cadmium and Oxidative Stress}

Cadmium is a well-recognized environmental pollutant with numerous adverse health effects. It principally affects lung, liver, kidney, and testes following acute intoxication, and nephrotoxicity, immunotoxicity, osteotoxicity and tumors on prolong exposures. Reactive oxygen species (ROS) are often implicated in Cd-induced deleterious health effects. There are direct evidence of the generation of free radicals 
in animals following acute Cd overload, and indirect evidence of involvement of ROS in chronic Cd toxicity and carcinogenesis. Cd-generated superoxide anion, hydrogen peroxide, and hydroxyl radicals in vivo have been detected by the electron spin resonance spectra, which are often accompanied by activation of redox sensitive transcription factors (e.g., NF- $\kappa \mathrm{B}, \mathrm{AP}-1$ and Nrf2) and alteration of ROSrelated gene expression. It is generally agreed upon that oxidative stress plays important roles in acute $\mathrm{Cd}$ poisoning.

However, direct evidence for oxidative stress is often obscure following long-term and environmentally-relevant low levels of Cd exposure. Alterations in ROS-related gene expression during chronic exposures are also less significant compared to acute $\mathrm{Cd}$ poisoning. This is probably due to induced adaptation mechanisms such as overexpression of metallothionein and glutathione following chronic $\mathrm{Cd}$ exposures, which in turn diminish $\mathrm{Cd}$-induced oxidative stress. In chronic Cd-transformed cells, less ROS signals are detected with fluorescence probes. Acquired apoptotic tolerance renders damaged cells to proliferate with inherent oxidative DNA lesions, potentially leading to tumorogenesis. Thus, ROS are generated following acute Cd overload that play an important roles in tissue damage. Adaptation to chronic Cd exposure reduces ROS production, but acquired $\mathrm{Cd}$ tolerance with aberrant gene expression plays important roles in chronic $\mathrm{Cd}$ toxicity and carcinogenesis.

The basic mechanisms involved in cadmium carcinogenesis are gene regulation of proto-oncogenes [46], oxidative stress [47-51], disruption of cadherins, inhibition of DNA repair and interference with apoptosis [52]. Cadmium is a potent cell poison, and known to cause oxidative stress by increasing lipid peroxidation and/or by changing intracellular glutathione levels. It affects the ubiquitin/ATPdependent proteolytic pathway. However, the cellular mechanisms involved in cadmium toxicity are still not well understood, especially in neuronal cells. The treatment of neuronal cells culture with different concentrations of the metal ion to examine the relationship between cadmiuminduced oxidative stress and the ubiquitin/ATP-dependent pathway revealed decreased glutathione levels, and marked increases in protein-mixed disulfides (Pr-SSGs) [53]. The increases in intracellular levels of Pr-SSGs were concurrent with increases in the levels of ubiquitinated proteins (Ub proteins) when the HT4 cells were subjected to lower ( $25 \mu \mathrm{m}$ or less) concentrations of cadmium. However, higher concentrations of cadmium $(50 \mu \mathrm{m})$ led to increases in Pr-SSGs but inhibited ubiquitination, probably reflecting inhibition of ubiquitinating enzymes.

The cadmium-induced changes in Pr-SSGs and Ub proteins are not affected when more than $85 \%$ of intracellular glutathione is removed from the cells by the glutathione synthetase inhibitor l-buthionine- $(S, R)$-sulfoximine. However, the reducing agent dithiothreitol, that prevents buildup of Pr-SSGs in the cell also blocks the accumulation of Ub proteins induced by cadmium. In addition, dithiothreitol blocks the effects of higher $(50 \mu \mathrm{m})$ concentrations of cadmium on cytotoxicity and on glutathione, Pr-SSGs, and Ub proteins. Together, these results strongly suggest that changes in the levels of intracellular Pr-SSGs and ubiquitin-protein conjugates in neuronal cells are the responses closely associated with the disruption of intracellular sulfhydryl homeostasis caused by cadmium-mediated oxidative stress.

The testis is the important target organ of Cd toxicity. Many studies indicate that $\mathrm{Cd}$ induces testicular damage in many species of animals including mice, hamsters, rabbits, guinea pigs and dogs [54, 55]. Cadmium has profound effect on sex organ weight, a primary indicator of possible alteration in androgen status [56,57]. Several mechanisms of $\mathrm{Cd}$-induced testicular toxicity have been proposed. Lafuente et al. [58] reported increased $\mathrm{Cd}$ accumulation in the hypothalamus, pituitary, and testis and decreased plasma levels of follicle stimulating hormone in rats, suggesting a possible effect of $\mathrm{Cd}$ on the hypothalamic-pituitary-testicular axis.

Several studies also suggest participation of reactive oxygen species (ROS) in Cd-induced testicular damage [59]. Both acute and chronic Cd exposure is associated with elevated lipid peroxidation in the lung, brain, kidney, liver, erythrocytes, and testis [60-64]. The reactive oxygen species (ROS) play both beneficial and harmful roles in living organisms [65]. ROS can be generated by both exogenous and endogenous sources. Cadmium is one of the exogenous sources shown to indirectly produce ROS in various cell lines [66-68]. The production and accumulation of ROS inhibit the electron transfer chain in mitochondria [69]. In general, the accumulated ROS consists of various amounts of hydrogen peroxide, hydroxyl ions, singlet oxygen, superoxide anions, lipid hydroperoxides, phospholipid hydroperoxides, and so forth. Excessive production of ROS disturbs the balance between the ROS and antioxidant agents (enzymes and antioxidant substances) in the cells. Hydrogen peroxide is the common substrate for catalase and GPx enzymes in the cells. While catalase decomposes $\mathrm{H}_{2} \mathrm{O}_{2}$ into water and oxygen, GPx oxidizes GSH to GSSG by utilizing $\mathrm{H}_{2} \mathrm{O}_{2}$. Glutathione reductase (GR) is another enzyme required for the antioxidant defense mechanism in cells. It reduces GSSG into GSH. Both GPx and GR work in tandem in the cells in order to maintain the GSH/GSSG ratio at a steady state level. When the cells are under oxidative stress, catalase, GR and GPx respond by altering their activities.

\section{Amelioration of Lead- and Cadmium-Induced Oxidative Stress}

Abetment of lead and cadmium toxicity with rebalancing the impaired prooxidant/antioxidant ratio through supplementation of antioxidant nutrients are still not completely clear. However, evidences suggest significant protective effects of antioxidant nutrients such as vitamin-C, carotenoids, selenium, vitamin-E, and so forth.

Vitamin $C$ is a major antioxidant that scavenges the aqueous ROS by very rapid electron transfer that inhibits lipid peroxidation [21]. Administration of vitamin C significantly inhibits the lipid peroxidation levels of liver and brain, and increased the CAT levels of kidney in lead-exposed rats [17]. Lead-induced ROS production as examined by rat sperm chemiluminescence generation reduced by $40 \%$ with supplementation of $500 \mathrm{mg}$ vitamin $\mathrm{C} / \mathrm{l}$ drinking water 
[70]. Vitamin C supplementation in lead-exposed animals significantly reduces blood, liver, and renal lead levels, and associated biochemical changes indicating a significant protective action of vitamin $\mathrm{C}$ against toxic effects of lead on heme synthesis and drug metabolism [71]. The combination of vitamin $\mathrm{C}$ and thiamine have been proved effective in reducing lead levels in blood, liver, and kidney along with reduction in lead-induced inhibition in the activity of blood d-ALAD and blood zinc protoporphyrin [72].

There has been considerable debate concerning the relationship between vitamin $\mathrm{C}$ nutritional status and leadinduced toxic effects. Early reports suggest vitamin $\mathrm{C}$ as a possible chelator of lead, with similar potency to that of EDTA [8]. Vitamin and/mineral supplementation in African American women was found to reduce blood lead level (BLL) from 5.1 to $1.1 \mathrm{mg} / \mathrm{dl}$, which was negatively correlated with serum levels of vitamin E and C [73]. Ascorbic acid increases urinary elimination of lead and reduces the hepatic and renal lead burden in rats [74].

A cross-sectional study analyzed 4213 young and 15365 adult Americans with mean BLL of $2.5-3.5 \mathrm{mg} / \mathrm{dl}$, respectively. The BLL had inverse relationship with serum vitamin C [75]. Vitamin C supplementation resulted in small reductions in lead retention in 85 human volunteers who consumed a lead-containing drink [76]. However, workers occupationally exposed to lead, and with BLL ranged from 28.9 to $76.4 \mathrm{mg} / \mathrm{dl}$, supplementation of vitamin $\mathrm{C}$ and zinc did not significantly reduce BLL [77]. The vitamin C supplementation did not alter the blood and sperm lead levels in lead-treated rats with BLL of $36 \mathrm{mg} / \mathrm{dl}$ [70]. A recent report stated that rats treated with ascorbic acid did not reduce lead burden in the liver, kidney, brain, and blood [17]. Although it is biologically plausible that vitamin C may affect lead absorption and excretion, the effect is more obvious in low-exposed subjects with higher vitamin C supplementation. In humans and animals exposed to high levels of lead, the reduction of BLL by vitamin $\mathrm{C}$ is less significant.

Vitamin $\mathrm{E}$ is the generic term used to describe at least eight natural-occurring compounds that possess the biological activity of $\alpha$-tocopherol. The group is comprised of $\alpha-, \beta-, \gamma-$ and $\delta$-tocopherol and $\alpha-, \beta-, \gamma-$ and $\delta$-tocotrienol. RRR- $\alpha$-tocopherol has the highest biological activity [78], the other tocopherols and tocotrienols are less biologically active but they are at least as abundant as $\alpha$-tocopherol in certain foods [79]. Vitamin E is nature's major lipid soluble chain-breaking antioxidant that is known to protect biological membranes and lipoproteins from oxidative stress [80]. The main biological function of vitamin $\mathrm{E}$ is its direct influence on cellular responses to oxidative stress through modulation of signal transduction pathways [81]. One of the protective roles of vitamin $\mathrm{E}$ on lead-induced damage is prevention of lipid peroxidation and inhibition of SOD and CAT activities in liver [82]. In lead-exposed rats, supplementation of vitamin $\mathrm{E}$ and/or $\mathrm{C}$ reduced sperm ROS generation, prevented loss of sperm motility and oocyte penetration capacity [70]. The interaction between vitamin $\mathrm{E}$ and other antioxidants might have a more efficient protective action against lead toxicity. Vitamin $\mathrm{E}$ and $\mathrm{C}$ jointly protect lipid structures against peroxidation [83]. Although vitamin $\mathrm{E}$ is located in membranes and vitamin $\mathrm{C}$ in aqueous phases, vitamin $C$ is able to recycle oxidized vitamin E [84]. Vitamin $\mathrm{C}$ repairs the tocopherol radical, thus recovering the chainbreaking antioxidant capacity of vitamin E [83]. Vitamin $\mathrm{E}$ alone or in combination with conventional chelator, $\mathrm{CaNa}_{2}$ EDTA has been reported to decrease the lead-induced lipid peroxide levels in liver and brain in rats [17].

Carotenoids play a significant role in reduction of leadinduced stress in all species. The reaction of carotenoids with radicals is partly due to its roles in photosynthesis, thus electron transfer from $\beta$-carotene to P680, with the $\beta$-carotene being oxidized to its radical cation CAR [85]. Dietary $\beta$-carotene mediates prevention of lipid peroxidation, and reduces the incidence of many diseases including cancer, atherosclerosis, age-related macular degeneration, and multiple sclerosis [86, 87]. However, the generally accepted beneficial roles of carotenoids as antioxidants have been seriously challenged by the results from clinical trials that suggest deleterious effects of administered $\beta$-carotene in heavy smokers [88]. There have been considerable recent investigations in the interaction of $\beta$-carotene and other antioxidants [89].

The antioxidant effects of Spirulina fusiformis, bluegreen algae rich in $\beta$-carotene and SOD, against lead toxicity have been examined in the testes of Swiss mice. The antioxidant nutrients scavenged the free radicals after lead administration and ROS generation in mice testes [90]. Supplementation with multiple antioxidants including vitamin $\mathrm{C}$, vitamin $\mathrm{E}, \beta$-carotene, selenium, and zinc resulted in significant increase of SOD and GPx in 36 workers exposed to lead [91]. The interaction of carotenoids and carotenoid radicals with other antioxidants is of importance with respect to anti- and, possibly, pro-oxidative reactions of carotenoids. The nature of the reaction between the tocopherol $(\mathrm{TOH})$ and various carotenoids shows a marked variation depending on the specific tocopherol homologue, of which a-TOH is the most active. $\beta$-carotene radical interacts with vitamin $\mathrm{C}$ in the aqueous phase, and carotenoid radical are efficiently reconverted to the parent carotenoid by vitamin $C[89,92]$.

Interactions between zinc and lead have been investigated at absorptive and enzymatic sites [93]. Zinc and lead compete for similar binding sites on the metallothioneinlike transport protein in the gastrointestinal tract [94]. The competition between zinc and lead might decrease the absorption of lead, thus reducing lead toxicity. Dietary supplementation with zinc and in combination with ascorbic acid [95] and thiamine [96] reduces lead toxicity in humans. Zinc has an important role in spermatogenesis in the male reproductive system, and the most probable site of action is the primary spermatocyte. Zinc supplementation competes for and effectively reduces the availability of binding sites for lead uptake. In another study, zinc was administrated to lead-exposed rats along with chelating agents $\mathrm{CaNa}_{2}$ EDTA, succimer, and D-penicillamine. Zinc enhanced the efficacy of lead chelation by reducing the blood, hepatic and renal lead level, and overturning the inhibited activity on blood ALAD [97]. A recent study has shown prevention of $\delta$ ALAD inhibition and increased cellular SOD in the testis of 
lead-exposed rats following zinc supplementation [98]. The protective effects of zinc against testicular damage caused by lead might be due to competition between lead and zinc. There is still no strong and direct evidence to conclude that the beneficial effects of zinc are mediated by antioxidation.

Zinc is a trace element essential for living organisms. More than 300 enzymes require $\mathrm{Zn}$ for their activity. It plays an important role in the DNA replication, transcription, and protein synthesis, influencing cell division and differentiation [99]. Zn has a relationship with many enzymes in the body and can prevent cell damage through activation of the antioxidant system [100-102]. It is an essential component of the oxidant defense system and functions at many levels [103]. Zn deficiency increases lipid peroxidation in various rat tissues, whereas $\mathrm{Zn}$ supplementation corrects the impairment [102]. Cotreatment with $\mathrm{Cd}$ and $\mathrm{Zn}$ prevents damage to the testes from Cd exposure [104]. This suggests Cd interference in $\mathrm{Zn}$-related metabolic functions. The competitive mechanism of interaction and $\mathrm{Zn}$-induced metallothionein induction are the plausible mechanism behind protective effects of $\mathrm{Zn}$ against $\mathrm{Cd}$ toxicity. This is substantiated by the findings that $\mathrm{Cd}$ treatment decreases the testicular $\mathrm{Zn}$ concentration and elevates the levels of hepatic and renal metallothioneins [105]. Zn pretreatment can prevent of cadmium-induced testicular tumors which may be attributed to the ability of $\mathrm{Zn}$ to reduce the cytotoxicity of $\mathrm{Cd}$ in interstitial cells by enhancing efflux of $\mathrm{Cd}$ and decreasing accumulation of $\mathrm{Cd}$ in the nuclei of this target cell population in the rat testis [106]. So, Cd altered testicular function mediated through induction of oxidative stress could be reversed by administration of $\mathrm{Zn}$.

Selenium is a cofactor of GPx, a cyto-antioxidant enzyme. Selenium enhances the availability of GSH, which is one of the most abundant intrinsic antioxidants that helps in preventing lipid peroxidation and resultant cell damage. Lead exposure decreases the activity of GPx due to the interaction of lead with the essential selenocysteine moiety of the enzyme [107]. Protection against liver and kidney damage by selenium is attributed to enhanced antioxidant capacity of cells, as evidenced by increased SOD and GR activities and elevated GSH content following selenium supplementation [45]. The combination of selenium and other antioxidants has been shown to reduce oxidative stress in animals. DNA damage in the liver and spleen induced by fumonisin B1 was protected by the mixture of antioxidants coenzyme Q10, Lcarnitine, vitamin $\mathrm{E}$ and selenium in rats [108]. Combined administration of antioxidants containing selenium, vitamin $\mathrm{C}$, vitamin $\mathrm{E}, \beta$-carotene, and $\mathrm{N}$-acetyl cysteine has been reported to prevent both the diabetes- and galactosemiainduced elevation of oxidative stress in rats [109]. Despite the above findings, the beneficial role of selenium alone on leadinduced oxidative stress is still unclear in human studies.

\section{Conclusion}

Generation of highly reactive oxygen species aftermath of lead and cadmium exposure may result in systematic mobilization and depletion of the cell intrinsic antioxidant defenses. Formation of reactive oxygen intermediates beyond the scavenging capacity of these antioxidant defense mechanisms results in accumulation of harmful free radicals and likelihood of oxidative damage to critical biomolecules, such as enzymes, proteins, DNA, and membrane lipids. Several mechanisms have been proposed to mediate the oxidative stress caused by lead and cadmium, including disrupted pro-oxidant/antioxidant balance. Although many investigators have shown lead-induced oxidative damage, and some antioxidants were found to reduce lead toxicity, the mechanisms of dietary supplementation of antioxidants remain to be further clarified in lead-exposed humans or animals.

Evidences suggest that in presence of varying concentrations of cadmium, the mitochondrial enzymes are more effective in reducing various ROS than their cytoplasmic counterparts. This observation reveals that most oxidoreduction reactions take place in the mitochondria, leading to the formation of several ROS. As less ROS are produced in the cytoplasm, the activities of antioxidant enzymes in the cytoplasm are not as high as the mitochondrial enzymes with cadmium treatments. Thus, more oxidative stress is observed in the mitochondria than in the cytoplasm. Each antioxidant enzyme shows its own pattern of activation or inhibition upon exposure of cells to different concentrations of lead and cadmium.

\section{References}

[1] D. S. Bae, C. Gennings, W. H. Carter, R. S. H. Yang, and J. A. Campain, "Toxicological interactions among arsenic, cadmium, chromium, and lead in human keratinocytes," Toxicological Sciences, vol. 63, no. 1, pp. 132-142, 2001.

[2] C. Phillips, Z. Gyori, and B. Kovács, "The effect of adding cadmium and lead alone or in combination to the diet of pigs on their growth, carcase composition and reproduction," Journal of the Science of Food and Agriculture, vol. 83, no. 13, pp. 1357-1365, 2003.

[3] R. C. Patra, D. Swarup, R. Naresh, P. Kumar, P. Shekhar, and R. Ranjan, "Cadmium level in blood and milk from animals reared around different polluting sources in India," Bulletin of Environmental Contamination and Toxicology, vol. 74, no. 6, pp. 1092-1097, 2005.

[4] D. Swarup, R. C. Patra, R. Naresh, P. Kumar, and P. Shekhar, "Blood lead levels in lactating cows reared around polluted localities; transfer of lead into milk," Science of the Total Environment, vol. 347, no. 1-3, pp. 106-110, 2005.

[5] R. C. Patra, D. Swarup, R. Naresh et al., "Tail hair as an indicator of environmental exposure of cows to lead and cadmium in different industrial areas," Ecotoxicology and Environmental Safety, vol. 66, no. 1, pp. 127-131, 2007.

[6] I. A. Okada, A. M. Sakuma, F. D. Maid, S. Dovidemskas, and O. Zenebon, "Evaluation of lead and cadmium in milk due to environmental contamination in Paraiba valley region of South Estern Brazil," Raissade-Saude-Publica, vol. 31, pp. 140-143, 1997.

[7] R. J. Irwin, M. Van Mouwerik, L. Stevend, M. D. Seese, and W. Basham, "Environmental contaminants encyclopedia," National Park Service, Water Resources Division, Fort Collins, Colorado. Distributed within the federal government as electronic document, February 2003. 
[8] R. A. Goyer and M. G. Cherian, "Ascorbic acid and EDTA treatment of lead toxicity in rats," Life Sciences, vol. 24, no. 5, pp. 433-438, 1979.

[9] H. A. Ruff, M. E. Markowitz, P. E. Bijur, and J. F. Rosen, "Relationships among blood lead levels, iron deficiency, and cognitive development in two-year-old children," Environmental Health Perspectives, vol. 104, no. 2, pp. 180-185, 1996.

[10] J. Dressier, K. A. Kim, T. Chakraborti, and G. Goldstein, "Molecular mechanisms of lead neurotoxicity," Neurochemical Research, vol. 24, no. 4, pp. 595-600, 1999.

[11] P. E. De Silva, "Determination of lead in plasma and studies on its relationship to lead in erythrocytes," Brazilian Journal of Indigenous Medicine, vol. 38, pp. 209-217, 1981.

[12] F. Khalil-Manesh, H. C. Gonick, E. W. J. Weiler, B. Prins, M. A. Weber, and R. E. Purdy, "Lead-induced hypertension: possible role of endothelial factors," American Journal of Hypertension, vol. 6, no. 9, pp. 723-729, 1993.

[13] D. J. Humphreys, "Effects of exposure to excessive quantities of lead on animals," British Veterinary Journal, vol. 147, no. 1, pp. 18-30, 1991.

[14] R. P. Sharma and J. C. Street, "Public health aspects of toxic heavy metals in animal feeds," Journal of the American Veterinary Medical Association, vol. 177, no. 2, pp. 149-153, 1980.

[15] W. N. Rom, "Effects of lead on reproduction," in Proceedings of the Workshop on Methodology for Assessing Reproductive Hazards in the Workplace, P. F. Infante and M. S. Legator, Eds., pp. 33-42, Washington, DC, USA, 1980.

[16] I. Lancranjan, H. I. Popescu, O. GAvănescu, I. Klepsch, and M. Serbănescu, "Reproductive ability of workmen occupationally exposed to lead," Archives of Environmental Health, vol. 30, no. 8, pp. 396-401, 1975.

[17] R. C. Patra, D. Swarup, and S. K. Dwivedi, "Antioxidant effects of $\alpha$ tocopherol, ascorbic acid and L-methionine on lead induced oxidative stress to the liver, kidney and brain in rats," Toxicology, vol. 162, no. 2, pp. 81-88, 2001.

[18] H. Fu, X. B. Ye, J. L. Zhu et al., "Oxidative stress in lead exposed workers," in IARC Gargnano Conference, p. 2.3, 1999.

[19] S. Sarkar, P. Yadav, and D. Bhatnagar, "Lipid peroxidative damage on cadmium exposure and alterations in antioxidant system in rat erythrocytes: a study with relation to time," BioMetals, vol. 11, no. 2, pp. 153-157, 1998.

[20] R. C. Patra, D. Swarup, and S. K. Senapat, "Effects of cadmium on lipid peroxides and superoxide dismutasein hepatic, renal and testicular tissue of rats," Veterinary and Human Toxicology, vol. 41, no. 2, pp. 65-67, 1999.

[21] B. Halliwell and J. M. C. Gutteridge, "Protection against oxidants in biologyogical systems: the superoxide theory of oxygen toxicity," in Free Radical in Biology and Medicine, B. Halliwell and J. M. C. Gutteridge, Eds., pp. 86-123, Clarendon Press, Oxford, UK, 1989.

[22] S. J. Yiin and T. H. Lin, "Lead-catalyzed peroxidation of essential unsaturated fatty acid," Biological Trace Element Research, vol. 50, no. 2, pp. 167-172, 1995.

[23] S. O. Knowles and W. E. Donaldson, "Dietary modification of lead toxicity: effects on fatty acid and eicosanoid metabolism in chicks," Comparative Biochemistry and Physiology C, vol. 95, no. 1, pp. 99-104, 1990.

[24] L. J. Lawton and W. E. Donaldson, "Lead-induced tissue fatty acid alterations and lipid peroxidation," Biological Trace Element Research, vol. 28, no. 2, pp. 83-97, 1991.

[25] V. N. Adonaylo and P. I. Oteiza, "Pb promotes lipid oxidation and alterations in membrane physical properties," Toxicology, vol. 132, no. 1, pp. 19-32, 1999.
[26] J. P. Farant and D. C. Wigfield, "Biomonitoring lead exposure with $\delta$-aminolevulinate dehydratase (ALA-D) activity ratios," International Archives of Occupational and Environmental Health, vol. 51, no. 1, pp. 15-24, 1982.

[27] M. Hermes-Lima, V. G. R. Valle, A. E. Vercesi, and E. J. H. Bechara, "Damage to rat liver mitochondria promoted by $\delta$-aminolevulinic acid-generated reactive oxygen species: connections with acute intermittent porphyria and leadpoisoning," Biochimica et Biophysica Acta, vol. 1056, no. 1, pp. 57-63, 1991.

[28] M. Hermes-Lima, "How do $\mathrm{Ca}^{2+}$ and 5-aminolevulinic acidderived oxyradicals promote injury to isolated mitochondria?" Free Radical Biology and Medicine, vol. 19, no. 3, pp. 381-390, 1995.

[29] E. J. H. Bechara, "Oxidative stress in acute intermittent porphyria and lead poisoning may be triggered by 5aminolevulinic acid," Brazilian Journal of Medical and Biological Research, vol. 29, no. 7, pp. 841-851, 1996.

[30] T. Douki, J. Onuki, M. H. G. Medeiros, E. J. H. Bechara, J. Cadet, and P. D. Mascio, "DNA alkylation by 4,5-dioxovaleric acid, the final oxidation product of 5-aminolevulinic acid," Chemical Research in Toxicology, vol. 11, no. 2, pp. 150-157, 1998.

[31] T. Douki, J. Onuki, M. H. G. Medeiros, E. J. H. Bechara, J. Cadet, and P. Di Mascio, "Hydroxyl radicals are involved in the oxidation of isolated and cellular DNA bases by 5aminolevulinic acid," FEBS Letters, vol. 428, no. 1-2, pp. 9396, 1998.

[32] T. G. Rossman, "Cloning genes whose levels of expression are altered by metals: implications for human health research," American Journal of Industrial Medicine, vol. 38, no. 3, pp. 335-339, 2000.

[33] B. Quintanilla-Vega, D. Hoover, W. Bal, E. K. Silbergeld, M. P. Waalkes, and L. D. Anderson, "Lead effects on protamineDNA binding," American Journal of Industrial Medicine, vol. 38, no. 3, pp. 324-329, 2000.

[34] B. L. Vallee and D. D. Ulmer, "Biochemical effects of mercury, cadmium, and lead," Annual Review of Biochemistry, vol. 41, no. 10, pp. 91-128, 1972.

[35] J. M. Hsu, "Lead toxicity as related to glutathione metabolism," Journal of Nutrition, vol. 111, no. 1, pp. 26-33, 1981.

[36] Y. Ito, Y. Niiya, and H. Kurita, "Serum lipid peroxide level and blood superoxide dismutase activity in workers with occupational exposure to lead," International Archives of Occupational and Environmental Health, vol. 56, no. 2, pp. 119-127, 1985.

[37] C. McGowan and W. E. Donaldson, "Changes in organ nonprotein sulfhydryl and glutathione concentrations during acute and chronic administration of inorganic lead to chicks," Biological Trace Element Research, vol. 10, no. 1, pp. 37-46, 1986.

[38] M. Chiba, A. Shinohara, K. Matsushita, H. Watanabe, and Y. Ihaba, "Indices of lead-exposure in blood and urine of lead-exposed workers and concentrations of major and trace elements and activities of SOD, GSH-Px and catalase in their blood," Tohoku Journal of Experimental Medicine, vol. 178, no. 1, pp. 49-62, 1996.

[39] N. A. Lachant, A. Tomoda, and K. R. Tanaka, "Inhibition of the pentose phosphate shunt by lead: a potential mechanism for hemolysis in lead poisoning," Blood, vol. 63, no. 3, pp. 518-524, 1984.

[40] H. Gurer, H. Ozgunes, R. Neal, D. R. Spitz, and N. Ercal, "Antioxidant effects of $\mathrm{N}$-acetylcysteine and succimer in red 
blood cells from lead-exposed rats," Toxicology, vol. 128, no. 3, pp. 181-189, 1998.

[41] P. Cocco, S. Salis, M. Anni, M. E. Cocco, C. Flore, and A. Ibba, "Effects of short term occupational exposure to lead on erythrocyte glucose-6-phosphate dehydrogenase activity and serum cholesterol," Journal of Applied Toxicology, vol. 15, no. 5, pp. 375-378, 1995.

[42] H. Gurer and N. Ercal, "Can antioxidants be beneficial in the treatment of lead poisoning?" Free Radical Biology and Medicine, vol. 29, no. 10, pp. 927-945, 2000.

[43] B. B. Gelman, I. A. Michaelson, and J. S. Bus, "The effect of lead on oxidative hemolysis and erythrocyte defense mechanisms in the rat," Toxicology and Applied Pharmacology, vol. 45, no. 1, pp. 119-129, 1978.

[44] G. N. Schrauzer, "Effects of selenium antagonists on cancer susceptibility: new aspects of chronic heavy metal toxicity," Journal of UOEH, vol. 9, pp. 208-215, 1987.

[45] A. I. Othman and M. A. El Missiry, "Role of selenium against lead toxicity in male rats," Journal of Biochemical and Molecular Toxicology, vol. 12, no. 6, pp. 345-349, 1998.

[46] D. Hanahan and R. A. Weinberg, "The hallmarks of cancer," Cell, vol. 100, no. 1, pp. 57-70, 2000.

[47] F. Thévenod and J. M. Friedmann, "Cadmium-mediated oxidative stress in kidney proximal tubule cells induces degradation of $\mathrm{Na}^{+} / \mathrm{K}^{+}$-ATPase through proteasomal and endo- /lysosomal proteolytic pathways," FASEB Journal, vol. 13, no. 13, pp. 1751-1761, 1999.

[48] A. Piqueras, E. Olmos, J. R. Martínez-Solano, and E. Hellín, "Cd-induced oxidative burst in tobacco BY2 cells: time course, subcellular location and antioxidant response," Free Radical Research, vol. 31, pp. S33-S38, 1999.

[49] S. J. Stohs, D. Bagchi, E. Hassoun, and M. Bagchi, "Oxidative mechanisms in the toxicity of chromium and cadmium ions," Journal of Environmental Pathology, Toxicology and Oncology, vol. 20, no. 2, pp. 77-88, 2001.

[50] W. Wätjen and D. Beyersmann, "Cadmium-induced apoptosis in C6 glioma cells: influence of oxidative stress," BioMetals, vol. 17, no. 1, pp. 65-78, 2004.

[51] C. O. Ikediobi, V. L. Badisa, L. T. Ayuk-Takem, L. M. Latinwo, and J. West, "Response of antioxidant enzymes and redox metabolites to cadmium-induced oxidative stress in CRL1439 normal rat liver cells," International Journal of Molecular Medicine, vol. 14, no. 1, pp. 87-92, 2004.

[52] C. M. Shih, W. C. Ko, J. S. Wu et al., "Mediating of caspase-independent apoptosis by cadmium through the mitochondria-ROS pathway in MRC-5 fibroblasts," Journal of Cellular Biochemistry, vol. 91, no. 2, pp. 384-397, 2004.

[53] M. E. Figueiredo-Pereira, S. Yakushin, and G. Cohen, "Disruption of the intracellular sulfhydryl homeostasis by cadmium- induced oxidative stress leads to protein thiolation and ubiquitination in neuronal cells," Journal of Biological Chemistry, vol. 273, no. 21, pp. 12703-12709, 1998.

[54] K. W. Hew, W. A. Ericson, and M. J. Welsh, "A single low cadmium dose causes failure of spermiation in the rat," Toxicology and Applied Pharmacology, vol. 121, no. 1, pp. 1521, 1993.

[55] G. Xu and X. Z. Jiang, "Male reproductive toxicity of cadmium," Chinese Journal of Public Health, vol. 15, pp. 17$18,1996$.

[56] N. M. Biswas, R. Sengupta, G. R. Chatopadhyay, A. Choudhury, and M. Sarkar, "Effect of ethanol on cadmium-induced testicular toxicity in male rats," Reproductive Toxicology, vol. 15, pp. 699-704, 2001.
[57] J. W. Laskey and P. V. Phelps, "Effect of cadmium and other metal cations on in vitro Leydig cell testosterone production," Toxicology and Applied Pharmacology, vol. 108, no. 2, pp. 296-306, 1991.

[58] A. Lafuente, N. Márquez, M. Pérez-Lorenzo, D. Pazo, and A. I. Esquifino, "Pubertal and postpubertal cadmium exposure differentially affects the hypothalamic-pituitary-testicular axis function in the rat," Food and Chemical Toxicology, vol. 38, no. 10, pp. 913-923, 2000.

[59] P. I. Oteiza, V. N. Adonaylo, and C. L. Keen, "Cadmiuminduced testes oxidative damage in rats can be influenced by dietary zinc intake," Toxicology, vol. 137, no. 1, pp. 13-22, 1999.

[60] J. Klimczak, J. M. Wisniewska-Knypl, and J. Kolakowski, "Stimulation of lipid peroxidation and heme oxygenase activity with inhibition of cytochrome P-450 monooxygenase in the liver of rats repeatedly exposed to cadmium," Toxicology, vol. 32, no. 3, pp. 267-276, 1984.

[61] N. Sugawara and C. Sugawara, "Selenium protection against testicular lipid peroxidation from cadmium," Journal of Applied Biochemistry, vol. 6, no. 4, pp. 199-204, 1984.

[62] D. Manca, A. C. Ricard, B. Trottier, and G. Chevalier, "Studies on lipid peroxidation in rat tissues following administration of low and moderate doses of cadmium chloride," Toxicology, vol. 67, no. 3, pp. 303-323, 1991.

[63] T. Koizumi and Z. G. Li, "Role of oxidative stress in single-dose, cadmium-induced testicular cancer," Journal of Toxicology and Environmental Health, vol. 37, no. 1, pp. 2536, 1992.

[64] D. Bagchi, P. J. Vuchetich, M. Bagchi et al., "Induction of oxidative stress by chronic administration of sodium dichromate [chromium VI] and cadmium chloride [cadmium II] to rats," Free Radical Biology and Medicine, vol. 22, no. 3, pp. 471-478, 1997.

[65] M. Valko, M. Izakovic, M. Mazur, C. J. Rhodes, and J. Telser, "Role of oxygen radicals in DNA damage and cancer incidence," Molecular and Cellular Biochemistry, vol. 266, no. 1-2, pp. 37-56, 2004.

[66] D. J. Price and J. G. Joshi, "Ferritin. Binding of beryllium and other divalent metal ions," Journal of Biological Chemistry, vol. 258, no. 18, pp. 10873-10880, 1983.

[67] A. Szuster-Ciesielska, A. Stachura, M. Słotwińska et al., "The inhibitory effect of zinc on cadmium-induced cell apoptosis and reactive oxygen species (ROS) production in cell cultures," Toxicology, vol. 145, no. 2-3, pp. 159-171, 2000.

[68] M. Watanabe, K. Henmi, K. Ogawa, and T. Suzuki, "Cadmium-dependent generation of reactive oxygen species and mitochondrial DNA breaks in photosynthetic and nonphotosynthetic strains of Euglena gracilis," Comparative Biochemistry and Physiology, vol. 134, no. 2, pp. 227-234, 2003.

[69] Y. Wang, J. Fang, S. S. Leonard, and K. M. K. Rao, "Cadmium inhibits the electron transfer chain and induces reactive oxygen species," Free Radical Biology and Medicine, vol. 36, no. 11, pp. 1434-1443, 2004.

[70] P. C. Hsu, C. C. Hsu, M. Y. Liu, L. Y. Chen, and Y. L. Guo, "Lead-induced changes in spermatozoa function and metabolism," Journal of Toxicology and Environmental Health A, vol. 55, no. 1, pp. 45-64, 1998.

[71] A. G. Vij, N. K. Satija, and S. J. S. Flora, "Lead induced disorders in hematopoietic and drug metabolizing enzyme system and their protection by ascorbic acid supplementation," Biomedical and Environmental Sciences, vol. 11, no. 1, pp. 7-14, 1998. 
[72] S. J. S. Flora and S. K. Tandon, "Preventive and therapeutic effects of thiamine, ascorbic acid and their combination in lead intoxication," Acta Pharmacologica et Toxicologica, vol. 58, no. 5, pp. 374-378, 1986.

[73] W. L. West, E. M. Knight, C. H. Edwards et al., "Maternal low level lead and pregnancy outcomes," Journal of Nutrition, vol. 124, no. 6, pp. 981-986, 1994.

[74] M. Dhawan, D. N. Kachru, and S. K. Tandon, "Influence of thiamine and ascorbic acid supplementation on the antidotal efficacy of thiol chelators in experimental lead intoxication," Archives of Toxicology, vol. 62, no. 4, pp. 301-304, 1988.

[75] J. A. Simon and E. S. Hudes, "Relationship of ascorbic acid to blood lead levels," Journal of the American Medical Association, vol. 281, no. 24, pp. 2289-2293, 1999.

[76] E. B. Dawson and W. A. Harris, "Effect of ascorbic acid supplementation on blood lead levels," Journal of the American College of Nutrition, vol. 16, p. 480, 1997.

[77] R. Lauwerys, H. Roels, and J. P. Buchet, "The influence of orally-administered vitamin $\mathrm{C}$ or zinc on the absorption of and the biological response to lead," Journal of Occupational Medicine, vol. 25, no. 9, pp. 668-678, 1983.

[78] H. Weiser and M. Vecchi, "Stereoisomers of $\alpha$-tocopheryl acetate. II. Biopotencies of all eight stereoisomers, individually or in mixtures, as determined by rat resorptiongestation tests," International Journal for Vitamin and Nutrition Research, vol. 52, no. 3, pp. 351-370, 1982.

[79] A. J. Sheppard, J. A. T. Pennington, and J. L. Weihrauch, "Analysis and distribution of vitamin $\mathrm{E}$ in vegetable oils and foods," in Vitamin E in Health and Disease, L. Packer and J. Fuchs, Eds., pp. 9-13, Marcel-Dekker, New York, NY, USA, 1993.

[80] L. Packer, "Protective role of vitamin E in biological systems," American Journal of Clinical Nutrition, vol. 53, no. 4, pp. 1050S-1055S, 1991.

[81] A. Azzi, D. Boscoboinik, and C. Hensey, "The protein kinase C family," European Journal of Biochemistry, vol. 208, no. 3, pp. 547-557, 1992.

[82] S. S. Chaurasia and A. Kar, "Protective effects of vitamin E against lead-induced deterioration of membrane associated type-I iodothyronine 5'-monodeiodinase (5'D-I) activity in male mice," Toxicology, vol. 124, no. 3, pp. 203-209, 1997.

[83] G. R. Buettner, "The pecking order of free radicals and antioxidants: Lipid peroxidation, $\alpha$-tocopherol, and ascorbate," Archives of Biochemistry and Biophysics, vol. 300, no. 2, pp. 535-543, 1993.

[84] B. Frei, "Ascorbic acid protects lipids in human plasma and low-density lipoprotein against oxidative damage," American Journal of Clinical Nutrition, vol. 54, no. 6, pp. 1113-1118, 1991.

[85] A. Telfer, S. M. Bishop, D. Phillips, and J. Barber, "Isolated photosynthetic reaction center of photosystem II as a sensitizer for the formation of singlet oxygen. Detection and quantum yield determination using a chemical trapping technique," Journal of Biological Chemistry, vol. 269, no. 18, pp. 13244-13253, 1994.

[86] J. A. Mares-Perlman, W. E. Brady, R. Klein et al., "Serum antioxidants and age-related macular degeneration in a population-based case-control study," Archives of Ophthalmology, vol. 113, no. 12, pp. 1518-1523, 1995.

[87] E. Giovannucci and S. K. Clinton, "Tomatoes, lycopene, and prostate cancer," Proceedings of the Society for Experimental Biology and Medicine, vol. 218, no. 2, pp. 129-139, 1998.

[88] G. S. Omenn, G. E. Goodman, M. D. Thornquist et al., "Effects of a combination of beta carotene and vitamin A on lung cancer and cardiovascular disease," New England Journal of Medicine, vol. 334, no. 18, pp. 1150-1155, 1996.

[89] A. Mortensen, L. H. Skibsted, and T. G. Truscott, "The interaction of dietary carotenoids with radical species," Archives of Biochemistry and Biophysics, vol. 385, no. 1, pp. 13-19, 2001.

[90] D. Shastri, M. Kumar, and A. Kumar, "Modulation of lead toxicity by Spirulina fusiformis," Phytotherapy Research, vol. 13, no. 3, pp. 258-260, 1999.

[91] V. Machartova, J. Racek, J. Kohout, V. Senft, and L. Trefil, "Effect of antioxidant therapy on indicators of free radical activity in workers at risk of lead exposure," Vnitrni Lekarstvi, vol. 46, pp. 444-446, 2000.

[92] A. Mortensen and L. H. Skibsted, "Relative stability of carotenoid radical cations and homologue tocopheroxyl radicals. A real time kinetic study of antioxidant hierarchy," FEBS Letters, vol. 417, no. 3, pp. 261-266, 1997.

[93] S. J. S. Flora, V. K. Jain, J. R. Behari, and S. K. Tandon, "Protective role of trace metals in lead intoxication," Toxicomanies, vol. 13, no. 1-2, pp. 51-56, 1982.

[94] J. H. Kagi and B. L. Vallee, "Metallothionein: a cadmium and zinc-containign protein from equine renal cortex. II. Physico-chemical properties," The Journal of biological chemistry, vol. 236, pp. 2435-2442, 1961.

[95] R. Papaioannou, A. Sohler, and C. C. Pfeiffer, "Reduction of blood lead levels in battery workers by zinc and vitamin C," Journal of Orthomolecular Psychiatry, vol. 7, no. 2, pp. 94-106, 1978.

[96] S. J. S. Flora, S. Singh, and S. K. Tandon, "Thiamine and zinc in prevention or therapy of lead intoxication," Journal of International Medical Research, vol. 17, no. 1, pp. 68-75, 1989.

[97] S. J. S. Flora and S. K. Tandon, "Beneficial effects of zinc supplementation during chelation treatment of lead intoxication in rats," Toxicology, vol. 64, no. 2, pp. 129-139, 1990.

[98] N. Batra, B. Nehru, and M. P. Bansal, "The effect of zinc supplementation on the effects of lead on the rat testis," Reproductive Toxicology, vol. 12, no. 5, pp. 535-540, 1998.

[99] C. J. Frederickson, "Neurobiology of zinc and zinccontaining neurons," International review of neurobiology, vol. 31, pp. 145-238, 1989.

[100] S. R. Powell, "The antioxidant properties of zinc," Journal of Nutrition, vol. 130, no. 5, pp. 1447s-1454s, 2000.

[101] A. Ozturk, A. K. Baltaci, R. Mogulkoc et al., "Effects of zinc deficiency and supplementation on malondialdehyde and glutathione levels in blood and tissues of rats performing swimming exercise," Biological Trace Element Research, vol. 94, no. 2, pp. 157-166, 2003.

[102] G. Ozdemir and F. Inanc, "Zinc may protect remote ocular injury caused by intestinal ischemia reperfusion in rats," Tohoku Journal of Experimental Medicine, vol. 206, no. 3, pp. 247-251, 2005.

[103] M. Sato and I. Bremner, "Oxygen free radicals and metallothionein," Free Radical Biology and Medicine, vol. 14, no. 3, pp. 325-337, 1993.

[104] A. A. Shaheen and A. A. El-Fattah, "Effect of dietary zinc on lipid peroxidation, glutathione, protein levels and superoxide dismutase activity in rat tissues," The International Journal of Biochemistry \& Cell Biology, vol. 27, pp. 89-95, 1995.

[105] E. Bonda, T. Włostowski, and A. Krasowska, "Testicular toxicity induced by dietary cadmium is associated with decreased testicular zinc and increased hepatic and renal 
metallothionein and zinc in the bank vole (Clethrionomys glareolus)," BioMetals, vol. 17, no. 6, pp. 615-624, 2004.

[106] T. Koizumi and M. P. Waalkes, "Effects of zinc on the distribution and toxicity of cadmium in isolated interstitial cells of the rat testis," Toxicology, vol. 56, no. 2, pp. 137-146, 1989.

[107] A. Valenzuela, J.-M. Lefauconnier, J. Chaudiere, and J.M. Bourre, "Effects of lead acetate of cerebral glutathione peroxidase and catalase in the suckling rat," NeuroToxicology, vol. 10, no. 1, pp. 63-70, 1989.

[108] F. Atroshi, A. Rizzo, I. Biese et al., "Fumonisin B1-induced DNA damage in rat liver and spleen: effects of pretreatment with coenzyme Q10, L-carnitine, $\alpha$-tocopherol and selenium," Pharmacological Research, vol. 40, no. 6, pp. 459467, 1999.

[109] R. A. Kowluru, R. L. Engerman, and T. S. Kern, "Diabetesinduced metabolic abnormalities in myocardium: effect of antioxidant therapy," Free Radical Research, vol. 32, no. 1, pp. 67-74, 2000. 

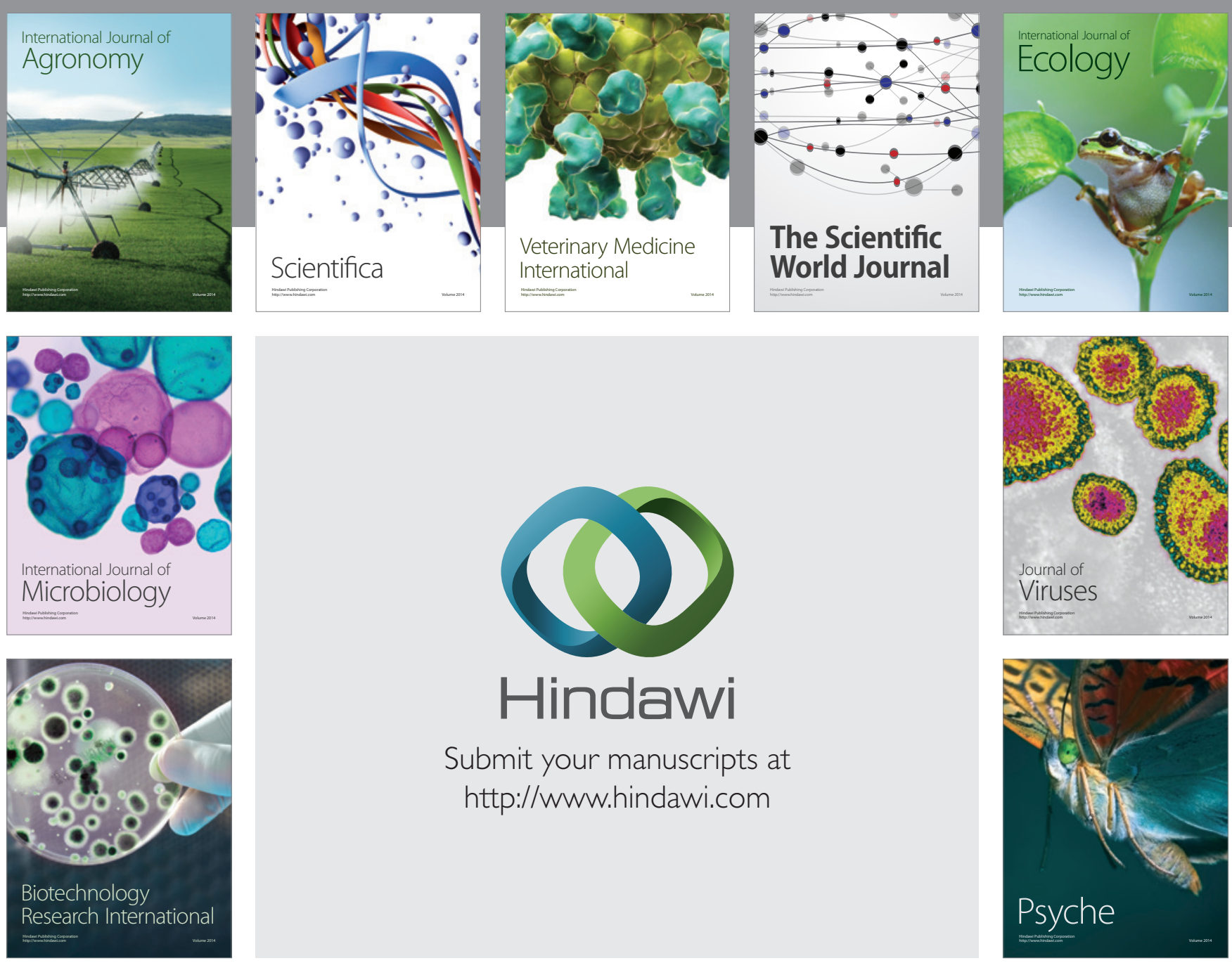

Submit your manuscripts at

http://www.hindawi.com
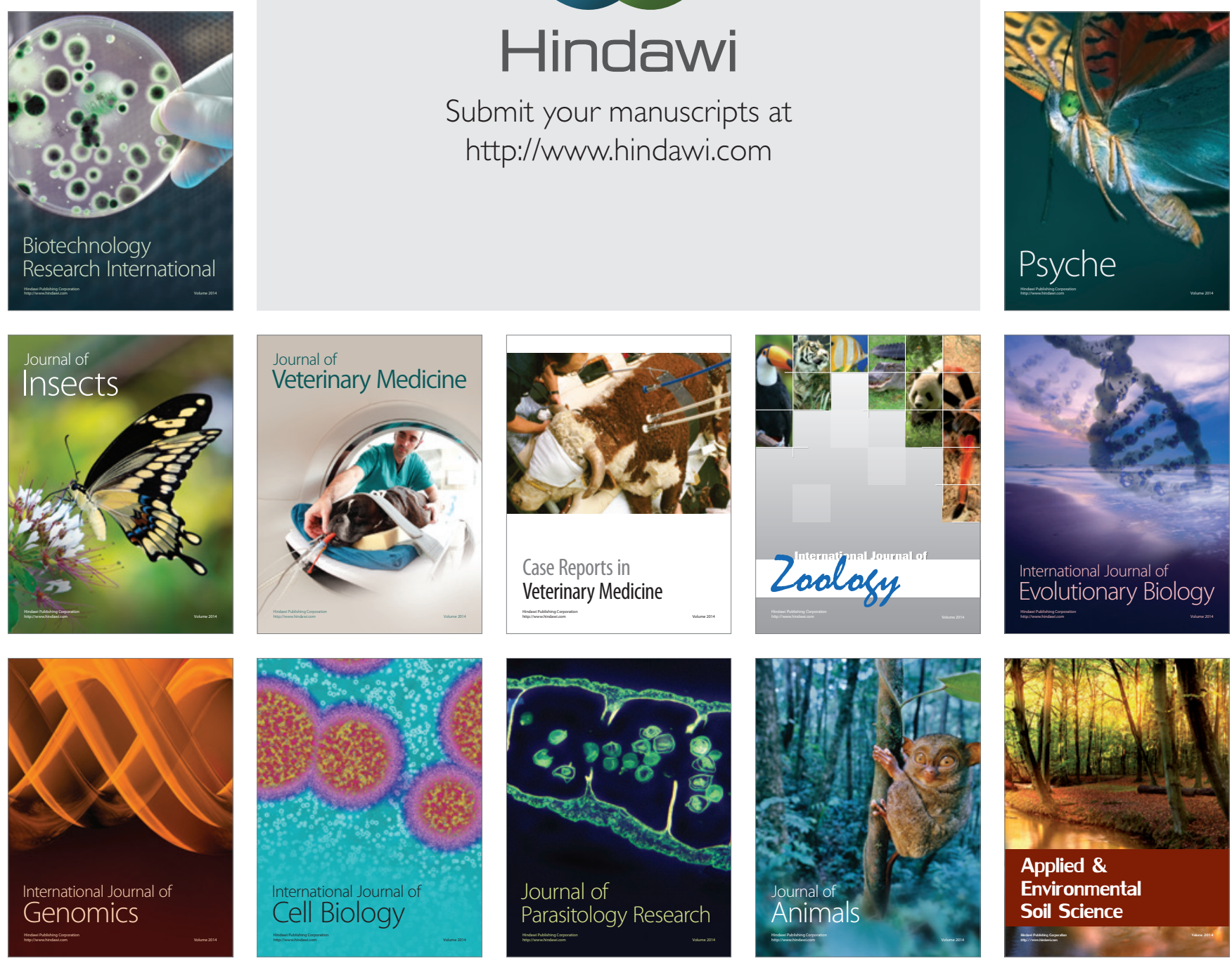